\title{
Opening movements in Ophuls: long takes, leading characters and luxuries
}

Book or Report Section

Accepted Version

Gibbs, J. (2017) Opening movements in Ophuls: long takes, leading characters and luxuries. In: Gibbs, J. and Pye, D. (eds.) The long take: critical approaches. Palgrave Close Readings in Film and Television. Palgrave Macmillan, London, UK, pp. 89-102. ISBN 9781137585721 Available at https://centaur.reading.ac.uk/72314/

It is advisable to refer to the publisher's version if you intend to cite from the work. See Guidance on citing.

Publisher: Palgrave Macmillan

All outputs in CentAUR are protected by Intellectual Property Rights law, including copyright law. Copyright and IPR is retained by the creators or other copyright holders. Terms and conditions for use of this material are defined in the End User Agreement.

\section{www.reading.ac.uk/centaur}

\section{CentAUR}

Central Archive at the University of Reading 
Reading's research outputs online 


\title{
Opening movements in Ophuls: long takes, leading characters and luxuries
}

\author{
John Gibbs
}

This chapter offers detailed observations on the orchestration of long takes and camera movement in the opening sequence of Caught (1949), making comparison to the opening shot of Madame de... (1953) and, briefly, to the first shot of the first "flashback" of Letter from an Unknown Woman (1948). All these instances share a concern with the subjectivity of the female protagonists and our relationship toward it, evoking the women's experience while balancing this with other kinds of perspective. As has been noted in the critical literature on Ophuls, and on melodramas of passion more generally, such views enable us to perceive the women concerned to be caught in a set of ideological frameworks of which they are at best partially aware. Among the interests of this particular comparison is the extent to which the dynamic around female subjectivity is played in relation to luxury goods, imagined, owned or admired.

As well as being one of the most important filmmakers for scholars exploring melodrama, Ophuls is central to the development of critical discussion of the long take. For some writers, the elegant elaboration of his films' visual style came to be seen as decorative: Lindsay Anderson is representative of Sight and Sound of the 1950s when he suggests, of Madame de ..., that Ophuls has "made the story an excuse for a succession of rich decorative displays" $(1954,197) .{ }^{1}$ In contrast, later critics saw in Ophuls' films a style precise and meaningful, the movement of the camera in complex long takes modulating relationships to the characters and their world in a complex interplay of involvement and distance. 
The openings of both Caught and Madame de... feature a shot in which the camera looks over a character's shoulder as she contemplates luxurious goods, and offers an off-screen commentary on the same. In Caught, two women choose furs and jewellery from a magazine, in a view which withholds, for the time being, that this activity is an aspirational game conducted from a cold-water flat. In Madame de... we watch Louise (Danielle Darrieux), the title character, determining which of a series of jewels and furs she feels she can most easily do without, to solve a pecuniary embarrassment. Letter from an Unknown Woman introduces its protagonist in a pair of long takes which “accompan[y] and observe," to adapt Andrew Britton's phrase, and note her fixation on a set of objects which come to shape her desires, her actions, and her notions of romance $(1982,99)$.

The title sequence of Caught adopts the optical point of view of an as yet unknown reader, as she turns the pages of Harper's Bazaar; the first shot after the titles takes up a view looking over the shoulder of two women flicking through the magazine. "Ummm...I'll take this one," comments the woman nearest to the camera, pointing to a bracelet in a jeweler's advertisement with her left hand, the fingers of her right, the only other part of her we can see, holding a cigarette. "That one," counters the other, pointing to an alternative bracelet. [Gibbs frame 1]

The framing of this shot is not as tight as the point of view shot of the titles, but what we can see is still extremely restricted. The view deliberately withholds clear access to context; the emphasis is on the turning pages and the off-screen dialogue; the candlewick bedspread, homely but hardly redolent of riches, is visible but easy to overlook in the playfulness of the women's actions and interactions. Is this for real or a 
game? Students over many years have tended to favour the former. In the flow of the moment it is calculatedly difficult to be certain.

As the conversation continues_-“Oh, Maud, isn't that stunning!," "I'd rather have mink" - the camera cranes out, and the material circumstances of the characters flood in: the two women now revealed are emphatically not in the market for mink or chinchilla, and share an apartment in which a bed abuts the kitchen. The movement out also takes us away from the companionable, over-the-shoulder view of the shot's opening, and the bed post rises into view as the camera settles, intervening between us and Maud. Point of view shot dissolves to a restricted viewpoint which then withdraws to a more distant perspective, enabling us to interpret and contextualise the action. [Gibbs Frame 2]

Maud (Barbara Bel Geddes) lies on the bed, head in hands, feet in the air, in the pose of a daydreaming child or adolescent. Maxine's feet (Ruth Brady's feet) remain on the ground: she is soon revealed to be more worldly than Maud, and here she appears more grown up, dressed in a silk or satin trouser suit, compared to Maud's blouse and rolled up jeans, and in the position of the parent at bedtime stories. The bed is bestrewn with other magazines, including Photoplay, suggesting that this is a habitual leisure pursuit. The new view of the scene also pictures Maud hemmed in by the ends of the bed and the shadow on the wall, offering us a different kind of perspective of Maud's situation, but one familiar to melodrama and the woman's film. In Ophuls' long takes, camera movements never have only one purpose.

Maxine stands and walks to the other end of the apartment, where she sits down at a card table, picks up a pencil, and asks Maud how much she spends on lunch every day. The camera tilts and pans to follow Maxine's movement, and, once she is seated, the film 
cuts through 180 degrees to show the opposite view of the narrow accommodation, tracking backwards as Maud walks to the bathroom in the distance, and settling with Maxine in the foreground. Equipped with a basin of water and a cylinder of bath salts, Maud returns, sits near her roommate and begins to soak her feet. [Gibbs Frame 3]

Maxine: "Well, if you don't spend more than a quarter a day for lunch, and you don't wear stockings, and if you don't go to the movies...

[Maud looks up]

...unless somebody takes you, you can go to school. Oh, yes - and you can’t buy any more magazines."

Maud: “Gee, maybe it isn't worth it."

Maxine: "Maybe you want to spend the rest of your life as a carhop, huh?"

The combination of long take, composition in depth, and deep focus achieved here present the characters in a material space and in relation to each other, where an edited treatment — such as reverse field cutting of the conversation — would have abstracted these relationships. The extraordinary photography of Lee Garmes enables everything from Maxine at the card table through to the sink at the other end of the flat to remain in focus. As well as the constraints of an apartment where tights dry on a chair back and a foldable card table is the only space for writing, we get a sense of their comfortable and established relationship_ - it isn't the heat that's made Maud's feet swell, "it's the humidity," they chorus in a moment, clearly returning to a familiar observation.

At the same time, the coherent sense of space that long takes enable allows the way the different areas of the flat are organised dramatically to be gradually revealed. 
The kitchen, contiguous with the foreground space in this shot, where Maxine does the accounts that determine the financial basis of Maud's aspirations to attend charm school, and Maud soaks her feet after a long day at work, is the space of material and financial reality.

The bed remains the space of fantasy. Later in the sequence Maud retreats here, the camera tracking in, in the words of V.F. Perkins, "to construct an isolated image of Maud-at-dreaming" $(1990,6)$. One can almost feel the absorption as the camera edges in, the score fading to a silence which makes the intensity of the moment more apparent, and which makes room on the soundtrack for the delicate undercutting that Maud's thoughts will receive from the "noises off," to quote Perkins again, "not just Maxine's harsh interjections but also the grubbily material sound of clattering plates and sloshing water from her dish washing" $(1990,6)$. This piece of action culminates in Maud absently playing with a fly-swat as she imagines the outcome of attending Dorothy Dale's charm school: encountering a handsome young millionaire while modelling in a Department store.

Maud: "And he's standing at the perfume counter, and then suddenly he turns around and sees me ... and we don't say a word for a long time... and then he says..."

Maxine: "Will you start drying the dishes?

The title sequence, with the pages turning for the benefit of the camera, gently alludes to a convention deployed in beginning fables and fairy tales on screen, so familiar by 2001 that it can be roundly spoofed in Shrek. It forms the first element of a pattern which defines the fantasy to which Maud is in thrall to be informed by the romance 
embodied by Perrault's telling of Cinderella. Maud's business with the fly swat, so beautifully analysed by Perkins (1990, 5-6), creates a character who does not, in her predatory cum naive cum romantic reverie, express her desires directly, but through catching a man's - a millionaire's - attention; the key point of the fantasy, underlined by the most emphatic, but still unconscious, thwack of the fly swat, is on sees me.

Like Lisa, in Letter from an Unknown Woman, Maud can only articulate her desire in the forms of traditional romance, where her efforts - from saving to go to charm school to the personal reconstruction that implies — construct an image which will then catch the eye of the man, allowing him to play his part in a romantic story in which he occupies the leading role, and in which the labour is disguised in the perfect romantic moment. For both Lisa and Maud these constructions prove to have unintended and unwelcome consequences.

The close-up of Dorothy Dale's brochure, representing Maud's optical point of view, gives us another tighter framing, echoing the shot of Harper's Bazaar. The promise of the charm school's copy is clearly part of the fantasy too, one which Maud falls for hook, line and sinker. And like the passage in which Maud is isolated on the bed, this closer framing is also counterbalanced by a skeptical off-screen voice, this time Maud's own: "Hmmm... she looks like a pretty nifty number-I bet this was retouched." Here Maud reveals a partial awareness and the film an observation perhaps more widely applicable: that one can be aware of the artifice involved in the construction of fashion images, and swallow the fantasy at the same time.

These structures—of closer views and wider revelations, the tensions between on and off-screen space — do not merely shape this sequence, but play out in following 
scenes: the tight framing which opens the third sequence reveals a fur coat and then Maud, or Leonora as she has renamed herself while at Dorothy Dale, smartly dressed in the elevator of a department store. Have her dreams already achieved fulfilment? But again, broader perspectives emerge as she moves onto the shop floor and the camera's view becomes more encompassing, revealing that she is merely modeling the coat, and to customers who pay her no attention whatsoever. Moments later, encountering Franzi, the handsome millionaire's "personal assistant," at work procuring young women to attend boat parties, the situation is reversed to make Maud's body the object of exchange, rather than the coat. ${ }^{2}$

Madame de..., made in France four years later, also shows a critical interest in financial exchange at the expense of women, and does so by means of a series of long takes with increasingly complex camera movement. These tracking shots chart Louise's movements and the wider transactions around the earrings, a gift from her husband the day after their wedding, which, to quote Andrew Britton, "by their circulation, define at every point the relations between the film's protagonists" $(1982,98)$. Focusing attention on the tensions of the opening sequence shot, one can observe some similarly suggestive play with camera movement, framing and tensions between on and off-screen space.

Following two title cards which end the opening credits, and which draw attention to the importance of ces bijoux for the story which follows, the film fades from black to the sight and sound of a gloved hand opening a drawer on a jewellery case: the drawer contains a pair of pendant earrings, a cut stone in one catching the light as it moves. The hand reaches for the left-hand earing, pauses, and then drops onto the leading edge of the drawer. An off-screen voice sighs, "If only they weren't the ones he gave me the day 
after our wedding." The fingers tap for a moment and then move to the right, the camera panning and tilting slightly to reveal a small chest — containing a fan, a purse, letters and jewellery — which the hand opens and then hovers above, before again tapping, indecisively: "What should I do?” [Gibbs frame 4]

Still without showing more than the woman's forearm, the camera follows the hand until it opens the mirrored door of a wardrobe. The hand leaves the frame with the departing door, and the camera tilts up the drawers inside, past feathers and fragrance bottles, before tilting down and tracking right, passing the shadow of its owner, a hint of her reflection, and catching up with the arm as it opens a second wardrobe, this one filled with dresses and topped with a shelf of hats, and books. The same movement is repeated, this time the mirror on the door showing a little of the woman's waist and skirts before the third wardrobe opens to reveal a row of furs.

As well as the observations the woman makes to herself, and the gentle underscoring of the scene, we can also hear humming and singing. Moreover, the humming responds to the score of the film, and they then play in relation to each other as a call and response. One musical phrase takes the form of words, as the camera surveys the cupboard full of dresses: "All this won't get me 20, 000 francs."

The shot continues to accompany the woman, just to her side, showing her arm but also the objects of her commentary and reflection as she moves back to the left, having announced that she loves her furs too much to part with them. We see a fleeting view of the back and side of her face as she closes the wardrobe and returns toward the hats and again when she chooses a hat, after retrieving a bible she has dislodged from shelf, but aside from this the camera continues to position itself so as to only show us her 
hand and forearm.

As the shot enters the final minute of its two and a half, she returns to her dressing table and sits down, fixing the hat and veil, the camera tracking in, her face reflected in a mirror on the table. She moves to examine a necklace, holding it to her neck, the camera pulling back and showing Louise almost in profile: "Not this, I'd rather drown myself"; a cross is next rejected. Deciding on the earrings — "I care for them the least" — she holds them up to her ears, examining the effect in the mirror, then puts them in a small bag. Standing, she passes back in front of the wardrobes, the camera panning and dollying to show her walking to the end of her bed, where she picks up a handkerchief — a first view, full figure - and then pans as she heads for the door, a table and two armchairs visible in the intervening space. The humming returns on the soundtrack, though it does not appear as though Louise is making the sound.

This is a highly unusual introduction to star and leading character, even granting that opening sequences often demonstrate greater latitude for formal play than the films which follow — think of Strangers on a Train (Hitchcock, 1951), or La Ronde (Ophuls, 1950). The shot presents — most emphatically_Louise's marginalisation in favour of the contents of the wardrobes and jewellery cases. At the same time, the distance thereby created is counterbalanced by the ways in which the shot involves us with Louise: we accompany her, share something similar to her journey through the room, for the majority of its duration. The camera is in the service of Louise's movement; it shows us what she is contemplating, and the voice gives us a feeling for its owner, and an appreciation of her concerns. Even though Louise is almost completely effaced from the image, her offscreen comments guide us toward her way of understanding and evaluating the objects 
she encounters. Our view shares something of the companionable position from which we looked over Maud and Maxine's shoulder, almost able to join in their deliberation.

The singing, and humming, are a little perplexing when considered closely. I have suggested that it doesn't look as though Louise is humming when she crosses the room at the end, although it does sound like Darrieux's voice throughout. Nor can a character, especially one not appearing in a musical, normally perform a call and response with the soundtrack. Yet while this may not literally be Louise singing, the musical accompaniment, and the sentiments sung, feel closely in accord with Louise's perspective: close-miked and intimate, the film is in tune with her character at this point, and this contributes strongly the element of sympathetic involvement which is one dimension of the experience which the sequence provides.

Even in the later stages of the shot, as she becomes more of a physical presence within it, our best view of Louise's face remains a reflection, in an excessively ornate mirror, the frame of which overwhelms the reflective surface, and Louise's face is both surrounded and presented as a gilded object. As Andrew Britton put it, "she appears, both to herself and to us, in an absolutely objectified form, the crucial distinction being that our sight of her foregrounds the objectification" $(1982,99)$. Louise selects the earrings, but, as Andrew Britton observes,

Louise owns them only because she is owned in her turn; and it is the failure of coincidence between these two facts which have previously been reconciled - the fact that earrings are her property and therefore at her disposal, and the fact that they are her property only because she is her husband's wife - which initiates the movement of the narrative. $(1982,99)$ 
The restricted framings of the opening shot of Madame de... have an inverse but parallel relationship to the carefully varied views of Caught. Both sequences turn on the mystifying potential of the objects: in the one, purchases are rapidly revealed to be a fantasy, in the second, possessions turn out not to be at the disposal of the heroine after all, providing only an illusion of wealth, power and freedom. Maud's fur coat may ultimately be disposed of in Caught, in a far from uncomplicated conclusion, but the earnings of Madame de... prove more enduring than her, or the other characters.

Tensions between on and off-screen spaces and sounds are critical to the interest of the long takes under discussion. Camera movements subtly inflect the extent to which we are aligned (or otherwise) with the characters, and the ways in which their material circumstances are revealed to us, offering integrated perspectives on suggestively staged action and performances. The various dynamics in play create complex ways of seeing and an active role for the spectator, although by different means to the practices examined in other chapters in this book.

In the sequence from Caught it would be too simplistic to say that the closer views align us more directly with the experience of the characters, while the wider views give us a chance to see their behaviour in context - rather it is the balancing of closer and wider views, and of on and off-screen activity which is integral to achieving these complex perspectives. And the balancing of on-screen and off is also central to the effects achieved in the opening plan séquence of Madame de....

Caught's long takes gain from the benefits of seeing characters in space, and in relationship to that space and to each other, which more edited treatments and closer views would preclude. But they also actively shape our perception through camera 
movement, orchestrating the limits of what we can see, and creating significant patterns by using the edge of the frame in conjunction with arrangements within the dramatic space. While the perspectives on the characters that are offered to us in these ways exist only for the spectator, the sequences from both Caught and Madame de... resist the power of the close up to give us privileged insight. Even in the closer view of Maud with the fly swat, the action is presented at some distance, with the emphasis afforded by a character's unconscious behavior (through an actor's highly achieved performance, presented in a way which doesn't force our attention to its most significant elements) and its relationship to off-screen sound; closer framings are, if anything, marked by a withholding of information. At no point does a closer view achieve the rhetorical force of analytical editing imagined in Bazin's reflections on the strawberry shortcake sequence from The Magnificent Ambersons (Welles, 1942).

While the long takes and camera movements of Madame de... chart the network of social relations through which the characters move, they are less concerned with placing the characters in a material reality. The camera delights in the construction and artifice of the films' spaces, progressing through walls and floors with aplomb. The movement between Caught and Madame de... also invites reflection on the movement between studio Hollywood and an expression of related forms back in Europe, in the latter extended in their stylisation to extremes. For all their graceful artistry, the repetitions of key movements - around the opera, through the church, in and out of the jewelers - deliberately build an oppressive delicacy as the film progresses. Louise herself — with the exception of her desperate and exhausted effort to prevent the dueltends toward increasing stasis and exhausted inertia in her final scenes, till at last the 
camera traces her familiar journey through the church, without her.

\section{Afterword}

As readers may be aware, this chapter has a parallel life as a video essay, published by [in]Transition (issue 3.2). If the reader engages with videographic version of the argument, my hope is that the dynamic possibilities of the audiovisual form will be apparent: particularly the immediacy with which argument and evidence can be brought together, and the varied ways in which the critical argument can encourage the viewer to reflect on elements of the film as it plays past. Preparing the written version of the essay for this chapter involved writing a considerable amount of additional description, while reminding me of how much longer the chapter would have to be to capture all of the significant detail of the mise-en-scène of these sequences.

This is not to say that description loses its role in the audiovisual essay. Written or spoken commentary provides opportunities for a description which guides and shapes a perspective on the material, drawing attention to elements of a film's complexity and modes of address. Equally, the ordering and organising of the material in videographic work can encourage the viewer to perceive details and structures, contributing to a developing argument, without recourse to text or spoken words.

While never resolving the problem that faces all criticism, especially detailed criticism - that of the relationship between the experience of watching the film and of engaging with the analysis, where the latter inevitably disrupts the former - the audiovisual essay brings us closer to being able to capture and simultaneously reflect on the moving forms of film and television. Equally, we may embrace the possibilities which better emerge from written forms of criticism: extended reflection, enabled by the 
pause which the reader can take at will from the page, is not so naturally available as a mode when viewing and listening to a video, where medium and commentary imply a time-based engagement.

With special thanks to the many students who have discussed Caught with me over the years, to Andrew Britton and Douglas Pye, in whose seminars I first encountered the film, and to all at the Middlebury Videographic Workshop, June 2015.

\section{Works Cited}

Anderson, Lindsay. 1954. "Madame de ...” Sight and Sound 23 (4): 196-7.

Bazin, André. 1978 [1950]. Orson Welles: A Critical View. Translated by Jonathan Rosenbaum. London: Elm Tree Books/Hamish Hamilton Ltd.

Britton, Andrew. 1982. "Metaphor and Mimesis: Madame De ...” Movie 29/30: 91-107.

Gibbs, John. 2002. Mise-en-scène: Film Style and Interpretation. London: Wallflower.

_. 2013. The life of mise-en-scène: visual style and British film criticism, 1946-78. Manchester: Manchester University Press.

—. 2016. "Opening movements in Ophuls: Caught (and Madame de ...)." [in]Transition 3 (2). 
Perkins, V.F. 1990. "Must we say what they mean?: film criticism and interpretation." Movie 34/35: 1-6.

${ }^{1}$ Anderson is critical of the films Ophuls has made since La Ronde (1950), comparing them unfavourably with the American movies, and arguing that camera movement has become an end in itself. Having described the opening shot of Madame de..., he writes: All this quite intricate action is caught, with breathtaking precision, in a single, continuous shot. And so onward: the camera is never still; every shot has the tension of a conjuring trick. The sleight of hand is dazzling, but fatally distracting. $(1954,196)$

For a fuller discussion of this critical history see Gibbs 2013.

${ }^{2}$ See Gibbs $(2002,13-14)$ for further discussion of this exchange. 